\title{
A medicina vai à guerra: a missão médico-militar brasileira na França durante a Primeira Guerra Mundial (1918-1919) ${ }^{1}$
}

\author{
Medicine goes to war: the military-medical brazilian mission in France during World \\ War First (1918-1919)
}
La medicina va a la guerra: la missión médico-militar brasilera en Francia durante la Primera Guerra Mundial (1918-1919)

Cristiano Enrique de Brum*

\section{Resumo}

Durante a Primeira Guerra Mundial, o governo brasileiro organizou e enviou uma Missão Médico-Militar para a França, a fim de fundar um hospital em Paris, colaborando, assim, com a causa brasileira na Guerra, por meio da medicina. Esse pelotão médico, organizado às pressas, em meio a escândalos e percalços diversos, se faz presente em diversas partes da França, atuando com cuidados médicos sobre civis e militares e, especialmente, auxiliando no combate à Gripe Hespanhola, epidêmica em grande parte do mundo, inclusive na Europa em conflito. Procuramos aqui, apresentar, além da contextualização sobre o posicionamento brasileiro frente à Guerra, como se constituiu e quem compôs a Missão Médica brasileira, como transcorreu a viagem até a Europa, bem como a atuação daqueles médicos na França entre 1918 e 1919.

Palavras-chave: Primeira Guerra Mundial. Missão Médico-Militar brasileira. França.

Doutorando em História da Pontifícia Universidade Católica do Rio Grande do Sul (PUCRS). Mestre em História pela Universidade do Vale do Rio dos Sinos (Unisinos), graduado em História pela mesma Universidade. Tem experiência nas áreas de História da Saúde, História da Educação, Patrimônio Histórico. Atualmente é delegado regional da DEFENDER Oscip. Atualmente está realizando um estudo prosopográfico da Missão Médica brasileira enviada à França durante a Primeira Guerra Mundial. E-mail: cristianodebrum@defender.org.br

Recebido em 31/07/2014 - Aprovado em 30/07/2014 http://dx.doi.org/10.5335/hdtv.14n.2.4574 


\section{Introducão}

Durante a Primeira Guerra Mundial, o governo brasileiro organizou e enviou uma Missão Médico-Militar para a França, a fim de fundar um hospital em Paris, colaborando, assim, com a causa brasileira na Guerra, por meio da medicina. Esse pelotão médico, organizado às pressas, em meio a escândalos e percalços diversos, se faz presente em diversas partes da França, atuando com cuidados médico sobre civis e militares e, especialmente, auxiliando no combate à Gripe Hespanhola, epidêmica em grande parte do mundo, inclusive na Europa em conflito.

Esse fato de natureza exótica, e até caricatural, aparentemente esquecido na historiografia, chama nossa atenção: trata-se do Brasil, um país latino-americano que, a fim de se inserir no conflito mundial que acontecia na Europa, envia médicos para a França, o país da medicina. $\mathrm{O}$ episódio, mesmo na época, acabou atraindo olhares desconfiados de jornalistas cariocas:

Todos sabem do escandalo. A imprensa annunciou ha tempos que o coronel deputado dr. Nabuco de Gouvêa, chefe da Missão medica que daqui partiu ha tempos para a França, fizéra em Pariz coisas do arco-da-velha, fundando um hospital maravilhoso, contratando enfermeiras entre mulheres da vida airada, fazendo das enfermarias cabarets, gastando rios de dinheiro, etc. [...] (A Missão..., 1919, p. 2).

Essas e outras acusações fizeram parte das notícias da imprensa nacional e estrangeira, relacionadas à atuação da Missão Médica Brasileira. Entretanto, para além das críticas, pretendemos compreender aqui o que foi essa missão e quais foram suas re- alizações no contexto da inserção do Brasil na Grande Guerra. Assim, procuramos aqui apresentar, além da contextualização sobre o posicionamento brasileiro frente à guerra, como se constituiu e quem compôs a Missão Médica Brasileira, como transcorreu a viagem até a Europa, bem como a atuação dessa na França entre 1918 e 1919.

\section{Brasil e 0 conflito mundial}

O conflito mundial, que havia iniciado em julho de 1914, já se arrastava por mais de dois anos, desgastando, cada vez mais, as forças das potências envolvidas. Alianças que se formavam, dentro e fora das trincheiras, de modo que as nações organizaram em dois grandes blocos: de um lado a Tríplice Aliança (composta da Alemanha, Áustria-Hungria, Itália), e da Tríplice Entente (formada pela França, Grã-Bretanha e Rússia). Enquanto isso, o Brasil continuava em uma posição de neutralidade frente ao conflito, entretanto, "nosso país foi o único neutro que protestou contra a invasão alemã na Bélgica" (COZZA, 1996, p. 97).

Na América Latina havia, até 1917, aquilo que Olivier Compagnon (2009) chama de um "consenso neutralista". Até aquele ano, países como Brasil e Argentina preferiam não se posicionar sobre o conflito por aparentes interesses econômicos. De 1917 em diante, a situação mudou devido ao posicionamento alemão de bloqueio e a temida campanha submarina que esta impunha contra os neutros.

No Brasil com o decorrer da Guerra, 
[...] foram organizados pelo país vários grupos de apoio à França e seus coligados na guerra, como o Comitê dos Aliados no Estado da Bahia, e a Liga pelos Aliados, no Rio Grande do Sul. Eram grupos que reuniam, em sua maioria, intelectuais, e realizavam propaganda dos países aliados e críticas aos Impérios Centrais (PIRES, 2011, p. 6).

O mais conhecido desses grupos era a Liga Brasileira pelos Aliados, que com sua propaganda favorável à França, Inglaterra e cia, pressionava a tomada de um posicionamento claro do Brasil. Além disso, diversos navios mercantes brasileiros foram afundados pelos alemães, o que também contribuiu para a tomada de posição. Ainda em 1917, foram afundados os navios Paraná (abril), Tijuca, Lapa (ambos em maio), Acari e Guaíba (estes últimos em outubro).

Esses elementos contribuíram, progressivamente, para um posicionamento definitivo do Brasil frente ao conflito. Em fevereiro de 1917, iniciou rompendo relações comerciais com Alemanha, porém, reservando seu direito de neutralidade. Em abril do mesmo ano, o Brasil declarou o fim das relações diplomáticas com a Alemanha. E, finalmente, em 26 do mês de outubro de 1917, um decreto reconhece e proclama o estado de guerra iniciado pelo Império Alemão contra o Brasil.

A presença de diversos imigrantes alemães nos estados do Sul e Sudeste do Brasil em cidades como Curitiba, Porto Alegre e Rio de Janeiro os imigrantes ou descendentes de alemães desencadeou forte repressão e ataques públicos a esses supostos "germanófilos". ${ }^{2}$
Os torpedeamentos contra os navios brasileira causaram grande comoção na população brasileira e, após isso, o Brasil planejou uma série de ações para se inserir no conflito mundial. A mais conhecida medida envolveu a Marinha brasileira a criação da Divisão Naval de Operações de Guerra (conhecida como DNOG), constituída para realizar missões de apoio como patrulhamento e vigilância, apesar da dificuldade de composição da esquadra brasileira.

Foi enviado para Europa, ainda, um grupo de treze oficiais aviadores para treinamento e atuação junto aos exércitos estrangeiros. Esses oficiais ainda auxiliaram, posteriormente, com missões de guarnição de aeronaves inglesas. A realização desse esforço de capacitar aviadores e a compra de diversos hidroaviões possibilitou a organização da aviação naval brasileira, servindo de núcleo para a constituição de uma aeronáutica brasileira, com o passar dos anos.

Acontece que talvez a mais significativa (e desconhecida) das ações tenha sido a atuação de uma missão médica, que em caráter militar, enviou para a França dezenas de médicos e soldados que, ao tratar de feridos e atingidos pela Hespanhola, acabou por fundar um hospital na zona de guerra.

\section{AComposição da Missão Médica}

Sabe-se que, "em primeiro de junho de 1918, o chefe da legação da República Francesa no Brasil, Ministro Paul Claudel, formaliza, em nota ao Ministro das Relações Exteriores, doutor Nilo Peçanha, o pedido de missão médica" (COZZA, 1996, p. 105). A partir disso, com o avançar das negociações, 
ainda em meados de 1918, Peçanha anuncia que o país criará uma missão composta por militares e médicos. A seguir, o nome do médico e deputado José Thomaz Nabuco de Gouveia, foi anunciado como chefe da missão. Então, com o aval do Presidente da República, Venceslau Brás, é organizada pelo governo brasileiro a Missão Médico-Militar para a construção de um hospital temporário na zona de guerra.

Nas palavras de um dos componentes da missão, Mário Kroeff:

Nosso Govêrno viu nos médicos, seu melhor elemento para colaborar na causa dos Aliados, dando demonstração leal e positiva. E na guerra, o Brasil entrou pelo emblema da medicina, de nossa medicina, sempre sublime na intenção de salvar e socorrer o ser humano, qualquer que êle seja (KROEFF, 1969, p. 410).

Muito além da tentativa de colaborar com a causa dos aliados, as motivações do governo para essa missão eram múltiplas. Conforme lembram Hochman (2006, p. 63) e Oliveira (1990), esse é um momento de afirmação de movimentos nacionalistas. Desse modo, ir à guerra e levar médicos ao conflito bélico significava mostrar que a ciência brasileira era capacitada. Era o Brasil construindo um hospital no país da medicina do período. A missão representava o Brasil inserindo-se na modernidade internacional pela via da saúde.

A composição da Missão contava com serviços clínicos e cirúrgicos, farmácia, intendência, secretaria e enfermaria, reunindo médicos, farmacêuticos e militares em um total de 112 missionários. ${ }^{3}$ Em relatório apresentado após o retorno ao Brasil, o chefe da Missão, o médico e político José Thomaz Na- buco de Gouvêa lembra-se dos momentos de construção do corpo de partícipes civis:

Quando, portanto, tivemos de fazer a escolha das pessoas, reduzindo-as ao número determinado [...], o trabalho foi considerável, visto que tínhamos mais de duzentos nomes e apenas 86 logares (BRASIL..., 1919, p. 9).

Entre os membros médicos da Missão, figuravam profissionais destacados com anos de atuação, outros recém-formados e alguns ainda por se formar. Alguns deles eram professores de faculdades de medicina e famosos clínicos, outros eram desconhecidos neófitos no campo profissional. Cozza resulta que, "dez médicos, entre os mais considerados na nossa sociedade, foram comissionados no posto de tenente-coronel" (COZZA, 1996, p. 105). Assim, encontravam-se todos organizados em hierarquia militar, de acordo com a experiência no campo da medicina. Sabe-se que os lugares foram disputados pelos médicos com grande concorrência, fazendo-os recorrer a redes de relações para imprimir seus interesses. ${ }^{4}$ 


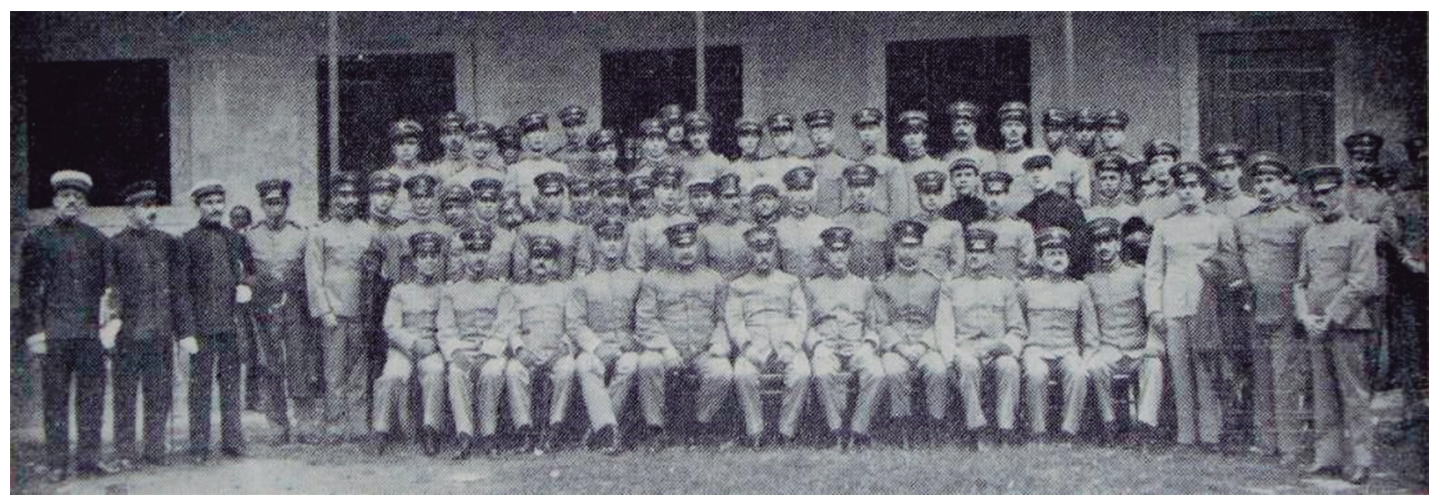

Fonte: KROEFF, 1971, p. 382.

Participar da guerra era um risco, mas sabemos das excelentes oportunidades que se escondem por trás desses delicados e aflitivos momentos. Participar de um corpo médico-militar, no momento de um conflito internacional, no velho continente, agregava ao currículo desses indivíduos vários capitais: capital político na negociação com o Estado (que poderia ajudar na promoção hierárquica), capital intelectual (no incremento em termos de capacidade profissional que essa experiência acarretaria) e capital simbólico (já que o espontâneo e desapegado voluntarismo cercaria os médicos-militares de uma aura de humanitarismo e coragem que os destacaria frente à sociedade em geral, incluindo aí potenciais pacientes).
Assim, crentes dos riscos e, possivelmente, colocando na balança as potencialidades que a participação naquele evento poderia acrescentar em suas trajetórias profissionais, foram aqueles médicos em direção à Europa.

\section{A viagem à Europa}

Após a escolha dos membros e a organização de todos os trâmites, foi realizada a partida da missão no dia 18 de agosto de 1918 a bordo do navio francês Plata. A partida da Missão foi acompanhada por milhares de pessoas junto ao porto do Rio de Janeiro, com calorosas e emocionadas homenagens aos brasileiros. 
Figura 2 - Aspecto do porto na partida da Missão à França

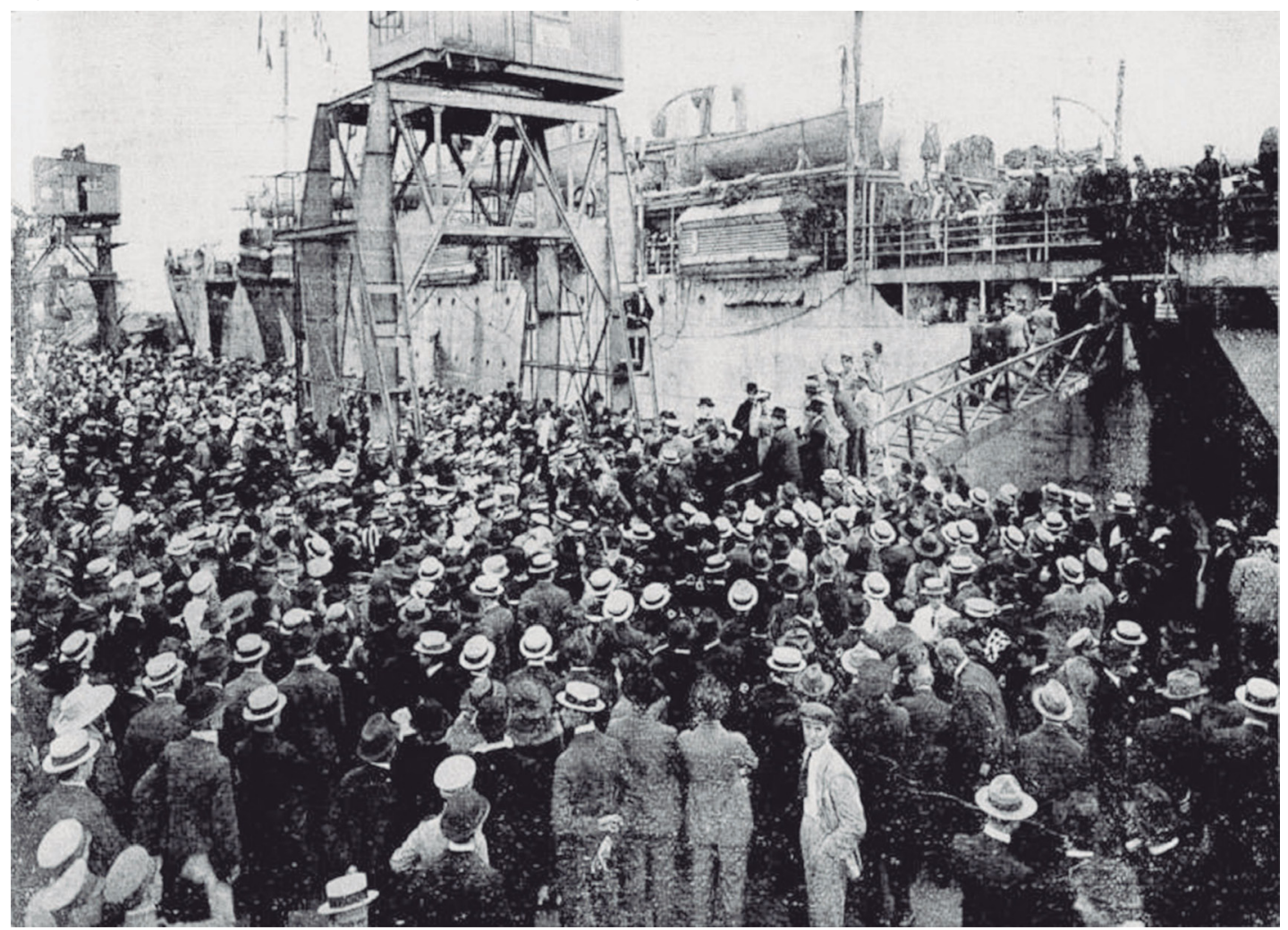

Fonte: A EMOCIONANTE..., 1918. p. 19.

A primeira escala da viagem após a travessia do Atlântico estava programada para a cidade de Dacar em Senegal, na África. Porém, em suas memórias, Mário Kroeff relata os percalços que apareceram no caminho:

A viagem decorreu lenta e morosa, com luzes apagadas, proibição de fumar no tombadilho à noite e os freqüentes e assustadores exercícios de salvamento. Ao nos aproximarmos à noite de Dacar, o comandante chamou Nabuco à ponte do comando e segredou-lhe que recebera ordens de mudar de rota, dirigindo-se ao Sul, para o porto da colônia inglêsa de Freetown, pois havia um submarino alemão à espera, para nos torpedear de madrugada, no dia se- guinte. [...] Dois dias depois, aportávamos em Freetown, onde perdemos vários dias, até que os inglêses se decidissem a abastecer de carvão o velho transporte francês. Desimpedido o caminho de Dacar, para lá seguimos afinal (KROEFF, 1971, p. 384).

Em Dacar, foram recebidos os brasileiros com brindes, espetáculos e banquetes que comemoravam a entrada do Brasil no conflito mundial (BRASIL..., 1919, p. 10). Entretanto, os festejos duraram pouco tempo, pois o período de duração da missão coincidiu com outro evento de alcance global: a gripe espanhola. Assim, mesmo antes de chegarem na Europa, durante a viagem, os 
missionários enfrentaram imprevistos relacionados à pandemia. Ainda no navio em direção ao velho continente, após terem saído de Dacar, alguns tripulantes começam a sofrer desse mal. Sobre isso, assim aponta o relatório da missão:

[...] os primeiros doentes julgaram-se victimas de uma grippe commum e banal [...]. Esses casos, porém, foram-se tornando cada vez mais numerosos. $\mathrm{O}$ espirito com que todos - mesmo os doentes - recebiam a notificação de novos casos de perfeito bom humor. Pouco a pouco viam-se mesas do refeitorio esvasiaram-se. Ninguem tinha até então imaginado que na realidade o que estava grassando a bordo era a terrivel pandemia hespanhola (BRASIL, 1919, p. 10-11).

Os outros destinos, antes de chegarem à França, incluíam a estratégica cidade de Gibraltar e também Oran, na Argélia. As duas cidades forneceram serviços para a desinfecção do navio em virtude da Hespanhola e, inclusive, cuidados médicos para os tripulantes doentes.

A notícia da morte de membros da missão que sucumbiram à Hespanhola chegou algum tempo depois no Brasil causando uma comoção generalizada. Entidades civis e instituições públicas enviavam notas aos jornais das capitais relatando o pesar que sentiam com a morte daqueles "heróis" brasileiros.

Após longa estadia em Oran e o registro de alguns médicos a menos na missão levados pela Gripe, o navio partiu para seu destino final: o porto de Marselha.

\section{Atuação da Missão}

Com algumas baixas no grupo inicial, chegaram, após escalas, à França, em 24 de setembro, e foram recebidos na cidade mediterrânea de Marselha por autoridades e médicos franceses (BRASIL, 1919, p. 11).

Após a chegada no país, o chefe dos médicos brasileiros, Nabuco de Gouveia se dirigiu até Paris, juntamente com parte dos membros, a fim de começar a organização inicial da missão. Entretanto, conforme apontou um anônimo participante da missão, a recepção na cidade não foi das melhores:

Le Matim de 30 de setembro noticiava a chegada do coronel Nabuco de Gouvéa a Paris sob o título: Missão Thetral Brasileira.

Sarcasmo proposital ou simples ironia da acaso, a verdade é que a apparencia espectaculosa que o deputado imprimia a seus actos justificava e justificou muitas vezes aquelle qualitativo (A Missão..., 1919, p. 3).

Após este episódio,

[...] uma vez em Paris, foram todos entregues ao alto comando francês que os distribuiu pelas Províncias, a fim de imediatamente prestarem serviço contra uma epidemia de gripe, que dizimava a população civil, enfraquecia a linha de frente e prejudicava a ação da retaguarda. [...] Enquanto uns eram assim espalhados pelo interior e cooperavam na saúde pública em geral, outros trabalhavam com o chefe da Missão, na montagem do Hospital Brasileiro, remodelando o prédio de um antigo convento de Jesuítas, que existia na rue Vaugirard (KROEFF, 1969, p. 413).

A composição desse hospital demorou várias semanas, até que ficasse pronto para receber os feridos e atingidos pela Hespanhola. Desde a escolha do prédio, a limpeza 
da área, reformas na estrutura do prédio, e montagem das alas e salas, tudo foi organizado pelos brasileiros com apoio do governo francês. Dificuldades diversas surgiram até se iniciarem os primeiros atendimentos. Em dados momentos, por exemplo, os brasileiros chegaram a disputar a conquista do prédio do novo hospital com os americanos:

A posse desse edifício não foi facil. Entre nós e o governo americano estabeleceu-se uma especie de concurrencia. Logo que os americanos souberam que pretendíamos alli installar um hospital, estabeleceram uma porfia conosco, tendo o governo francez tido necessidade de invocar a sua pala- vra empenhada comnosco para se vêr livre dos pedidos insistentes dos americanos, que, nesse momento, com grande quantidade de feridos vindos do "front", onde a luta atravessava uma phase intensíssima precissavam de hospital urgentemente (BRASIL..., 1919. p. 12).

O edifício logo foi oferecido aos brasileiros, com a contrapartida de que estes cuidassem tanto dos feridos de guerra quanto dos doentes pela Gripe. Esse hospital, além de prestar ajuda à assistência pública francesa, também serviu como uma espécie de quartel-general durante o período de guerra reunindo os missionários brasileiros.

Figura 3 - Hospital de Vaugirard

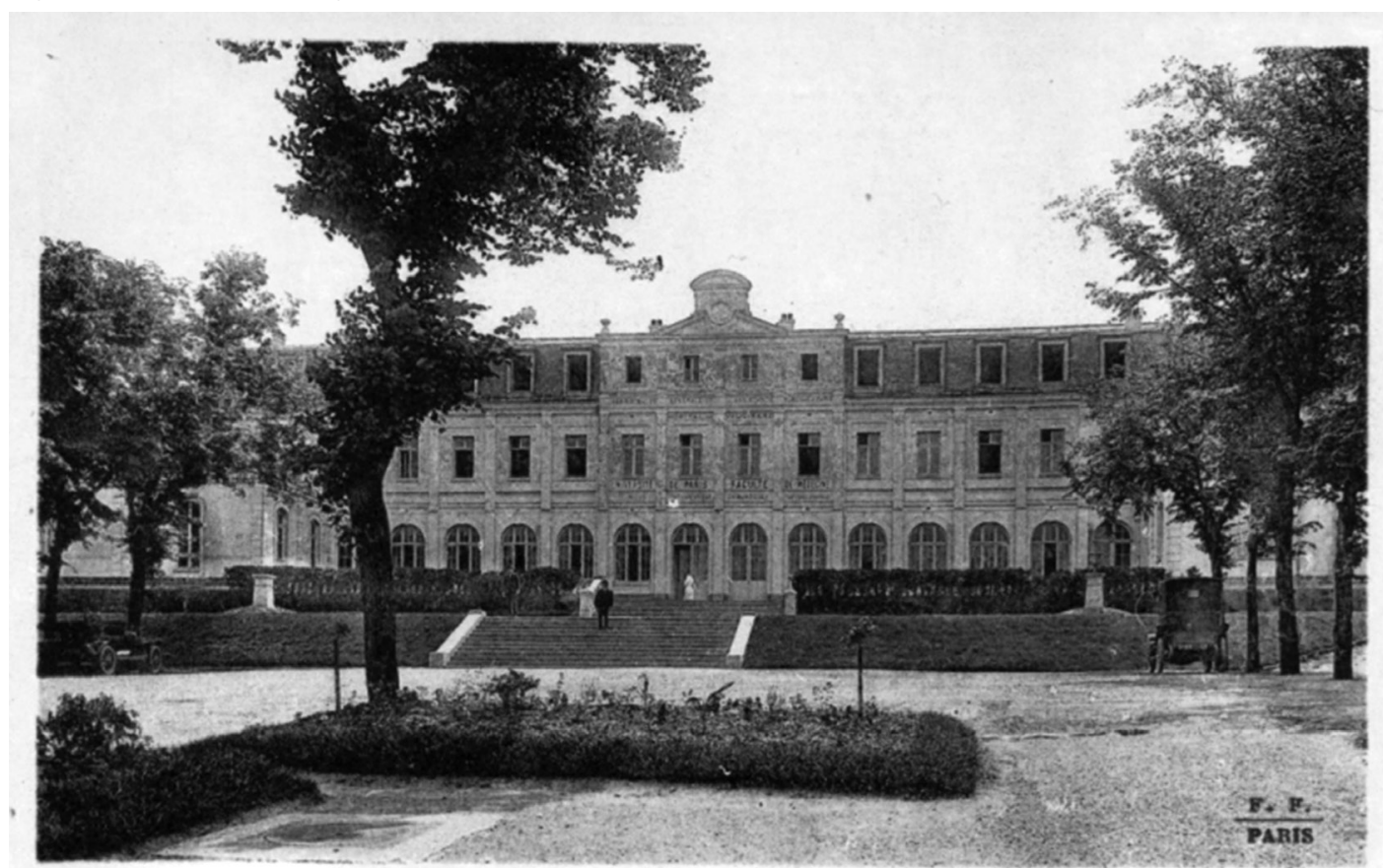

Paris (XV*) - Hôpltal de Vaugirard (Fondation Franco-Brésilienne)

Fonte: Acervo do autor 
O hospital, que deveria ter caráter temporário, continuou servindo à sociedade parisiense no pós-guerra, alternando sua administração entre as entidades religiosas e a assistência pública de Paris. Funcionou ainda ali durante alguns anos um setor de clínicas, terapêuticas e cirurgias da Faculdade de Medicina da Universidade de Paris ${ }^{5}$.

Por meio dos relatórios e relatos daqueles médicos combatentes torna-se difícil compreender como se dava a lógica de atendimento aos feridos e doentes que vinham do Front. Mas ao que aponta o relatório geral da missão, em um primeiro momento grande parte dos atendimentos realizados se vinculou aos combatentes que se encontravam na retaguarda que haviam sido atingidos pela gripe. Recorda o chefe da missão, que o governo francês pensou em

[...] utilizar immediatmente os nossos médicos para irem em socorro das guarnições militares das formações da rectaguarda, onde a grippe estava causando os mais pavorosos effeitos, collocando o governo em expectativa de vêr as suas forças immobilizadas quase em massa por centena de milhares de doentes (BRASIL..., 1919, p. 12).

Assim foram enviados diversos médicos brasileiros para atuar no apoio às guarnições de retaguarda, em um primeiro momento. Posteriormente, para o interior da França

[...] foram remettidas equipes, que foram postas á disposição dos chefes militares das respectivas regiões. Ahi passaram esses medicos longa temporada, prestando ums serviço inestimável, conquistando, gradativamente, a confiança das autoridades francezas, a ponto de serem muitos deles investidos da funcção de direcção e comando de hospitaes e de divisões sanitárias (BRASIL..., 1919, p. 13).
Os médicos foram enviados em diferentes momentos da missão e com funções diversas a cumprir em várias regiões da França. Além de Paris, montaram equipes de trabalho ou realizaram ações individuais nas seguintes cidades francesas: Besançon, Bordeaux, Bourges, Clermont-Ferrand, Le Mans, Limoges, Marselha, Montpellier, Nantes, Reims, Rennes e Tours.

Tempo depois, quando a guerra já dava sinais de estar próxima do fim, o Brasil finalmente enviou equipes para a linha de frente "onde sob as ordens do comando francez, seriam destacados para postos de socorro instalados na zona de batalha" (BRASIL..., 1919, p. 14).

Bonifácio Costa, por exemplo, membro do corpo principal da Missão, no posto de $2^{\circ}$ tenente, na função de médico auxiliar atuou no interior da França, juntamente com outros médicos indicados para a região de Bourges, segundo o Relatório da Missão (BRASIL..., 1919, p. 13). Além disso, daquele ponto em diante foi designado para a região de Nevers (KROEFF, 1969, p. 415), ao norte do país, onde trabalhou no Hospital de moléstias contagiosas da $8^{\mathrm{a}}$ região.

A missão começou a reduzir seu contingente de homens conforme aos poucos, e em março de 1919, já haviam retornado grande parte dos médicos da missão e encerrava-se a participação brasileira na guerra.

\section{Considerações finais}

Independentemente, das críticas sobre sua atuação ou organização, a importância da Missão Médica foi descrita por Rachel Motta Cardozo (2010; 2011) ao apontar que 
desdobramentos surgidos a partir da Missão tiveram consequências importantes na modernização do Exército brasileiro. Pois a partir dessa, criaram-se condições para a instituição de outra Missão que reformou serviços militares diversos, com a vinda de franceses para o Brasil. Além disso, autores sinalizaram que as ações diplomáticas entre os dois países foram fortalecidas após esse contato inicial realizado pela Missão Médica.

De qualquer maneira, o investimento realizado com a constituição da Missão e do Hospital Brasileiro de Vaugirard parece ter sido fundamental, também, para a inserção brasileira na Liga das Nações e nas conferências de paz no pós-guerra.

Sabe-se, ainda, que as relações científicas entre Brasil e França foram interrompidas durante a Grande Guerra, conforme apontam Magali Romero Sá et al. (2009, p. 248). Acreditamos, porém, que parte dessas relações foram reatadas com a construção do Hospital Brasileiro instalado pela Missão Médica, que após o conflito, entregue as autoridades francesas, e sob o comando do médico Pierre Duval, que durante a década de 1920 se prontificou a receber médicos brasileiros na instituição.

Entretanto, apesar de todo o esforço que o governo brasileiro realizou para se inserir no conflito, incluindo nisso a realização da Missão Médica, isto não "permitiu a emergência de uma memória da Grande Guerra" $^{\prime \prime}$ (COMPAGNON, 2009, p. 32) que durasse até os nossos dias. Veremos se esta situação irá se alterar neste e nos próximos anos quando estaremos comemorando o centenário da Guerra e a entrada do Brasil no conflito.

\section{Abstract}

During the period of First World War, the Brazilian government created and sent a medical and military mission to France, with the goal to found a hospital in Paris, to collaborate, this way, with the Brazilian cause through medicine. This medical brigade, hurriedly organized, in the middle of scandals and troubles, was in many French parts, fighting mainly against the Spanish Flu (1918's Influenza), epidemic all over the world, included Europe during the War. Our purpose here is to present a description of the historical background of the Brazilian position in the War, how the Brazilian Medical Mission was organized, who took part of it, how was the trip to Europe, as well as how those doctors act in France between 1918 and 1919.

Keywords: World War I; Brazilian Medical Mission; France.

\section{Resumen}

Durante la Primera Guerra Mundial, el gobierno brasilero organizó y envió una Misión Médico-Militar a Francia, con el fin de fundar un hospital en París, colaborando así Brasil en la guerra por medio de la medicina. Este pelotón médico, organizado de prisa, en medio de escándalos y percances diversos, se hizo presente en diversas partes de Francia, actuando con cuidados médicos sobre civiles y militares y, especialmente, auxiliando en el de la Gripe Española, epidémica en gran parte del mundo, incluso en la Europa en conflicto. Intentamos aquí pre- 
sentar, además de la contextualización sobre el posicionamiento brasilero frente a la guerra, como se constituyó y quién compuso la Misión Médica brasilera, como transcurrió el viaje hasta Europa, además de la actuación de aquellos médicos en Francia entre 1918 y 1919.

\section{Palabras clave: Primera Guerra Mundial;} Misión Médico-Militar brasilera; Francia.

\section{Notas}

1 Esse artigo, inédito, é resultado de uma primeira aproximação com o tema que estamos trabalhando em nosso projeto de doutorado, que realiza um estudo prosopográfico da Missão Médico-Militar brasileira.

2 Trabalhos como o de Márcio de Oliveira (Oliveira, 2012) e Stefan Chamorro Bonow (Bonow, 2011), utilizando, principalmente, dados coletados na imprensa mostram a delicada situação de desconfiança que se desenvolveu nas cidades de Curitiba e Porto Alegre junto às comunidades alemãs.

3 Esse é o número de missionários apontado pelo relatório oficial da missão, entretanto, sabe-se que ainda, cerca de 30 militares também acompanharam a missão com objetivo de proteger o prédio do hospital.

4 Na listagem desses duzentos médicos encontrava-se, por exemplo, Bonifácio Costa que, nesse momento, a fim de pleitear e garantir um dos lugares na missão, possivelmente, acionou ele elementos de sua rede de relações: dois professores dos tempos da Faculdade de Medicina que encontravam-se na organização da missão. José Thomaz Nabuco de Gouvêa, professor substituto na FMRJ na época de Bonifácio, foi o Chefe e principal organizador da missão; por sua vez, Bruno Alvares da Silva Lobo, professor da cadeira de microbiologia, também se enquadrava nas primeiras fileiras da hierarquia na missão.

5 Continua existindo, nos dias de hoje, o hospital nesse prédio, apesar de ter recebido inúmeras modificações, ampliações e descaracterizações em sua arquitetura ao longo dos anos. Atualmente, atende pelo nome de Hôpital Vaugirard Gabriel-Pallez, e serve à assistência pública parisiense, com especialidade em geriatria e, também, como um hospital universitário (Hôpital..., 2010-2011).

6 Tradução nossa.

\section{Referências}

BONOW, Stefan Chamorro. A desconfiança sobre os indivíduos de origem germânica em Porto Alegre durante a Primeira Guerra Mundial: cidadãos leais ou retovados? Porto Alegre, Tese (Doutorado em História), Programa de Pós-Graduação em História da Pontifícia Universidade Católica do Rio Grande do Sul - PUCRS, 2011.

CARDOSO, Rachel Motta. O Serviço de Saúde do Exército no período entreguerras. In: ENCONTRO REGIONAL DE HISTÓRIA DA ANPUH-RIO, XIV, 2010, Rio de Janeiro. Anais..., 2010. p. 1-16.

CARDOSO, Rachel Motta. Missões militares, política externa e relações diplomáticas: o Cone Sul e a busca pela modernização de seus exércitos. In: JORNADA DE PÓS-GRADUAÇÃO EM HISTÓRIA DAS CIÊNCIAS E DA SAÚDE, 1ª , 2011, Rio de Janeiro. Anais eletrônicos..., 2011. p. 1-10. Disponível em: <http:/www.jornadappghcs.coc.fiocruz.br/images/Anais_Eletronico/rachel_cardoso.pdf>. Acesso em: 16 jan. 2013.

COZZA, Dino Willy. A participação do Brasil na Primeira Guerra Mundial. Revista do Instituto Histórico e Geográfico Brasileiro, Rio de Janeiro, ano 157, n. 390, p. 97-110, jan./mar. 1996 COMPAGNON, Olivier. Entrer en Guerre? Neutralité et engagement de l'Amerique latine entre 1914 et 1918. Relations internationales, Paris. v. 1, n. 137, p. 31-43. jan. 2009.

HOCHMAN, Gilberto. A era do saneamento. São Paulo: Hucitec, 2006.

HÔPITAL Vaugirard Gabriel-Pallez. Bienvenue à l'hôpital Vaugirard - Gabriel-Pallez. Livret d'Accueil, 2010-2011. Disponível em: <http:/ / espacepatient.aphp.fr/files/2011/12/2010_ Vaugirard-BD.pdf>. Acesso em 16 jan. 2013.

KROEFF. Mário. Missão Médica Militar em França na Guerra de 1918. O Hospital, Rio de Janeiro, v. 75, n. 2, fev. 1969, p. 405-423. 
. A Missão Médica Militar em França. In: KROEFF, Mário. Imagens do meu Rio Grande. Rio de Janeiro: [s. n.], 1971.

OLIVEIRA, L. L. A Questão Nacional na Primeira República. São Paulo: Brasiliense/CNPq, 1990.

OLIVEIRA, Márcio de. A cidade de Curitiba e os imigrantes alemães durante a Primeira Guerra Mundial, uma análise da imprensa local. Cadernos CERU, série 2, v. 23, n. 2, p. 175202, dez. 2012.

PIRES, Livia Claro. A Liga Brasileira pelos Aliados e o Brasil na Primeira Guerra Mundial. In: SIMPÓSIO NACIONAL DE HISTÓRIA ANPUH, XXVI, 2011, São Paulo. Anais... São Paulo, jul. 2011. p. 1-15.

SÁ, Magali Romero; BENCHIMOL, Jaime L.; KROPF, Simone; VIANNA, Larissa; SILVA, André Felipe Cândido da. Medicina, ciência e poder: as relações entre França, Alemanha e Brasil no período de 1919 a 1942. História, Ciência, Saúde - Manguinhos, Rio de Janeiro, v. 16, n. 1, p. 247-161, jan./mar. 2009.

\section{Referências Documentais}

A EMOCIONANTE partida da Missão Médica. Revista da Semana, Rio de Janeiro, ano 19, n. 29, 24 ago. 1918. p. 19.

A MISSÃO medica em França. A União. Rio de Janeiro. 20 jun. 1919. p. 2.

A MISSÃO medica que o Brasil enviou à Europa. O que nos diz um dos seus membros, em cartas que de Paris nos remeteu. Correio da Manhã. Rio de Janeiro, 25 abr. 1919. p. 3.

BRASIL. Ministério da Guerra. Missão medica especial enviada á França em caracter militar - Relatório enviado ao Exmo. Sr. Ministro da Guerra pelo Dr. José Thomaz Nabuco de Gouvêa, chefe da missão em 18 de janeiro de 1919. Diário Official dos Estados Unidos do Brasil. Poder Executivo, Rio de Janeiro, Distrito Federal, 14 mar. 1919. Seção 1. p. 8-16. 